http://jmscr.igmpublication.org/home/ ISSN (e)-2347-176x ISSN (p) 2455-0450

crossref DOI: https://dx.doi.org/10.18535/jmscr/v7i12.62

\title{
Study of Clinical and Endoscopic Profile of Patients with Acute Upper Gastrointestinal Bleed
}

\author{
Authors \\ Dr Love Garg*, Dr Arjun Lal Kakrani, Dr Varsha Bhatt, Dr Manasi Harale \\ Department of General Medicine, Dr. D. Y. Patil Medical College, Hospital and Research Centre, Pimpri, \\ Pune, India \\ *Corresponding Author \\ Dr Love Garg \\ C1-1106 Mahindra Antheia, Nehrunagar, Pimpri, Pune-411018, India
}

\begin{abstract}
Background: Acute upper gastrointestinal bleeding is a common medical emergency with an estimated incidence of 50-150 cases per one lakh annually and it has been noted as a major cause of hospital admission and deaths worldwide ranging from $0.9 \%$ to $26.5 \%$.Hence, this study was aimed to know the clinical and endoscopic profile of patients presenting with acute upper GI bleed to our hospital and their possible etiologies.

Methods: This hospital based observational and cross-sectional study included sixty patients aged 18 years and above admitted in Department of General Medicine during the study period who presented with hematemesis or melena or both within 7 days.

Results: Among 60 patients, males were predominant (86.7\%). Mean age of presentation was $41.93 \pm$ 15.16 years. Most patients presented with both hematemesis and melena (51.7\%), $41.7 \%$ patients had hematemesis only and $6.7 \%$ patients had melena only. In our study, oesophageal varices were seen in $51.6 \%$ patients, portal hypertensive gastropathy in $33.3 \%$ patients, gastric ulcers in $11.7 \%$ patients and duodenal ulcers in $5 \%$ patients.

Conclusion: The majority of patients belonged to age group of 31-40 years with a male predilection and variceal bleed was the most common cause of Upper GI bleeding.

Keywords: Upper GI bleeding, oesophageal varices.
\end{abstract}

\section{Introduction}

Upper gastrointestinal bleeding (UGIB) is referred as the loss of blood occuring within intraluminal gastrointestinal tract from any location between upper oesophagus to duodenum proximal to the ligament of Treitz. ${ }^{(1)}$ UGIB has an estimated incidence of 50-150 cases per one lakh annually ${ }^{(2)}$ and it has been noted as a major cause of hospital admission and deaths worldwide ranging from $0.9 \%$ to $26.5 \%$. $^{(3)}$ Upper GI tract bleed is 5 times more common as compared to lower GI bleed. There are many causes of UGIB with peptic ulcer being the most common cause accounting for $50 \%$ to $70 \%^{(4)}$ followed by oesophageal varices which attributes approximately $6 \%$. However in some Indian studies ${ }^{(5,6)}$, variceal bleed is found to be the most common cause of upper GI bleeding followed by peptic ulcer. Other etiologies include Mallory-Weiss tear, gastritis and duodenitis, a arteriovenous malformations and malignancy. The 
primary test which is used for diagnosis of upper GI bleed is endoscopy, which has a sensitivity of 92-98\% and specificity of $30-100 \% .^{(7)}$ The analysis of clinical and endoscopic factors helps in assessment of risk factors, rational treatment planning and improved outcome. This study aimed to know the clinical profile and endoscopic profile of patients presenting with acute upper GI bleed to our hospital and their possible etiologies.

\section{Methods}

This hospital based observational and cross sectional study comprised of 60 patients admitted in Department of Medicine during study period. They were assessed according to clinical proforma. Laboratory investigations were done, including complete haemogram, Liver function tests, Renal function tests, Prothrombin time, Stool for occult blood, USG-abdomen. They underwent upper GI endoscopy, to detect changes in oesophagus, stomach and duodenum $\left(1^{\text {st }}\right.$ and $2^{\text {nd }}$ part) and multiple biopsy samples obtained from suspected or involved areas which includes fundus, antrum, greater and lesser curvature and duodenum ( $1^{\text {st }}$ and $2^{\text {nd }}$ part) and were also subjected to rapid urease test. Biopsy specimen were subjected to histopathological study. All patients were assessed by complete Rockall score irrespective of etiology.

\section{Inclusion Criteria}

All the patients aged 18 years and above who presented with hematemesis or melena or both within 7 days were included in the study.

\section{Exclusion Criteria}

1. Pregnant women.

2. Patients who did not give consent for endoscopic procedure.

\section{Procedure}

Approval was obtained from the Institutional Ethics Committee before commencing the study. A voluntary informed and written consent was taken from the participants and only those who gave consent were included in the study. All participants / relatives were explained regarding possible benefits as well as risk of study in detail. Consent form was available in English, Hindi and Marathi. In case of illiterate participants/relatives, consent was taken in presence of witness. The witness was considered to be anyone not directly attached to the study. The personal details of participants and information related to study was strictly kept confidential during study period at all levels. All patients were selected by a detailed history and physical examination. Patients with signs and symptoms suggestive of UGIB such as hematemesis, melena or both were included in the study. Endoscopy was performed in all patients and findings were noted.

\section{Data Analysis}

After collection of data, the forms of all patients were revised. Incomprehensible data was matched again with respective participant profile. Data was entered in MS Excel sheet for preparation of 'Master Chart'.

\section{Statistical Analysis}

Data was entered into computer Microsoft Excel and exported to SPSS version 20 for analysis. Continuous variables were expressed as mean \pm standard deviation or median and range. Categorical variables were expressed as frequency and percentage. Chi square or Fisher exact test was used for association between exposure(Age, sex and risk factors) and outcome (Severity of bleeding and Rockall scale outcome) variable in case of categorical variables. $\mathrm{P}$ value was considered statistically significant when it was less than 0.05

\section{Results}

A total of 60 patients of UGIB were included in the study.

Table 1: Age distribution of study subjects

\begin{tabular}{|l|c|c|}
\hline Age group (years) & Frequency & Percent \\
\hline $15-20$ & 2 & 3.4 \\
\hline $21-30$ & 14 & 23.3 \\
\hline $31-40$ & 19 & 31.7 \\
\hline $41-50$ & 10 & 16.7 \\
\hline $51-60$ & 8 & 13.3 \\
\hline $61-70$ & 5 & 8.5 \\
\hline$>70$ & 2 & 3.4 \\
\hline Total & 60 & 100.0 \\
\hline
\end{tabular}


This table shows age wise distribution of study subjects. Maximum (31.7\%) study subjects were in age group of 31-40 years with mean age of $41.96 \pm 15.16$ years and range of $18-82$ years.

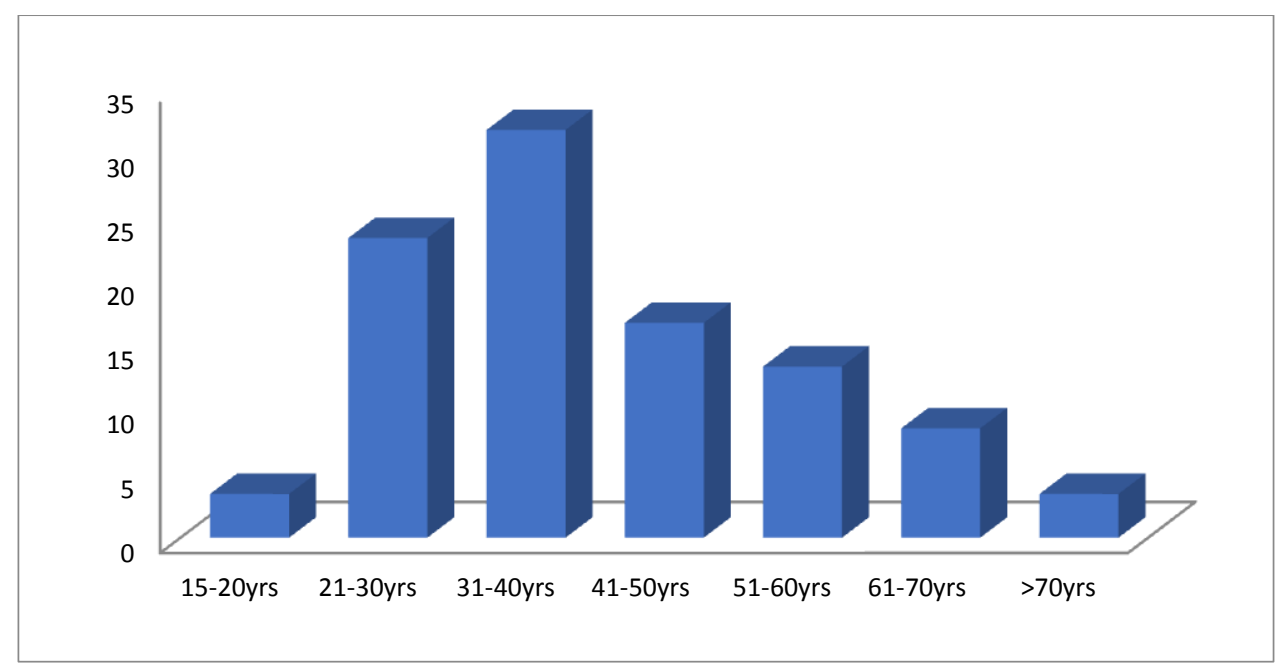

Figure 1: Age distribution of study subjects

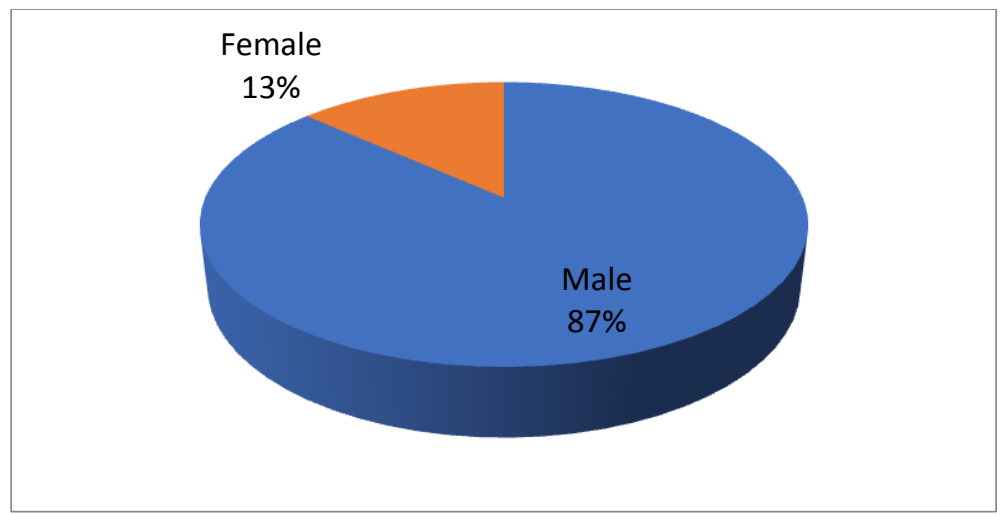

Figure 2: Gender distribution of study subjects

Table 2: Clinical presentation among study subjects

\begin{tabular}{|l|c|c|}
\hline Clinical presentation & Frequency & Percent \\
\hline Hematemesis + Melena & 31 & 51.7 \\
\hline Hematemesis & 25 & 41.7 \\
\hline Melena & 4 & 6.7 \\
\hline
\end{tabular}

Table 3: Risk factors among study subjects

\begin{tabular}{|l|c|c|}
\hline Risk factors & Frequency & Percent \\
\hline Alcoholism & 39 & 65.0 \\
\hline Smoking & 9 & 15.0 \\
\hline NSAIDs & 5 & 8.3 \\
\hline Hepatitis B Surface antigen & 1 & 1.7 \\
\hline Hepatitis C & 1 & 1.7 \\
\hline No risk factors & 5 & 8.3 \\
\hline
\end{tabular}

This table shows that more than half of patients had alcoholism (65\%) as a risk factor for upper GI bleeding and $8.3 \%$ were NSAIDs users. 


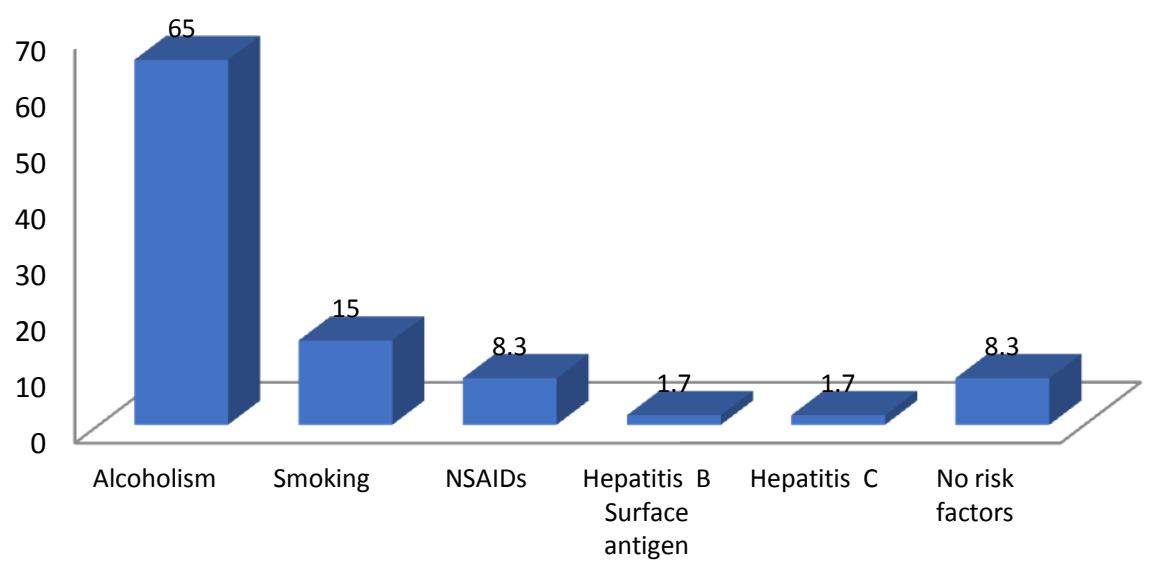

Figure 3: Risk factors among study subjects

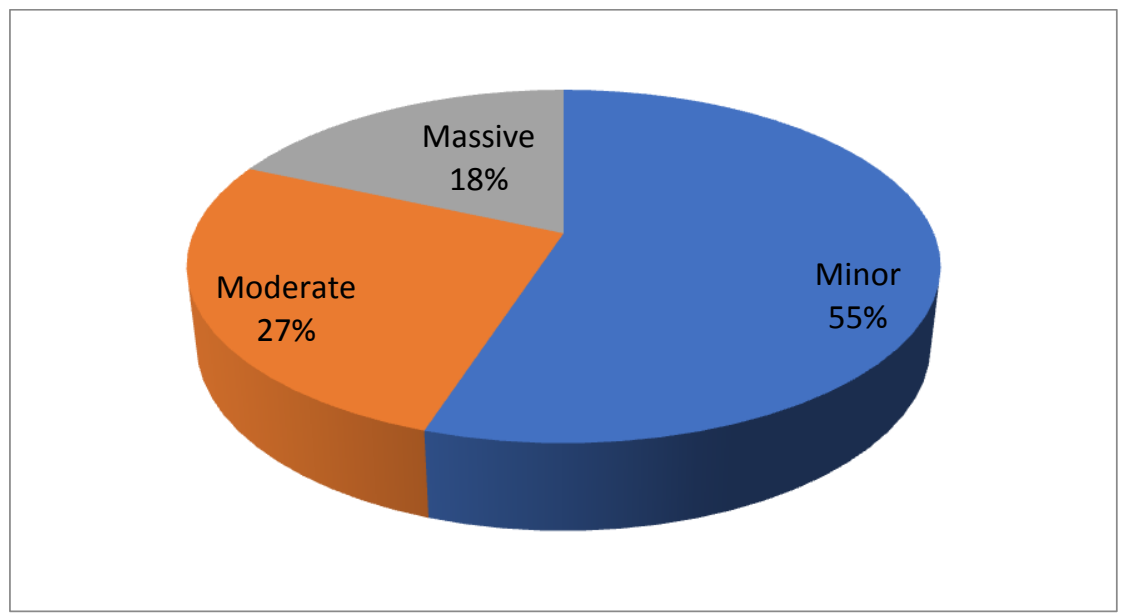

Figure 4: Severity of bleeding among study subjects

Table 4: USG findings among study subjects

\begin{tabular}{|l|c|c|}
\hline USG Findings & Frequency & Percent \\
\hline Portal vein collaterals & 30 & 50.0 \\
\hline Ascites & 26 & 43.3 \\
\hline Spleen enlargement & 24 & 40.0 \\
\hline Shrunken liver & 21 & 35.0 \\
\hline Coarse echo texture of liver & 16 & 26.6 \\
\hline Liver enlargement & 13 & 21.7 \\
\hline Hepato-splenomegaly & 7 & 11.6 \\
\hline
\end{tabular}

Table 5: OGDscopy findings among study subjects

\begin{tabular}{|l|c|c|}
\hline OGDscopy Findings & Frequency & Percent \\
\hline Oesophageal Varices & 31 & 51.6 \\
\hline Portal hypertensive gastropathy & 20 & 33.3 \\
\hline Hemorrhagic gastritis & 8 & 13.3 \\
\hline Gastric ulcer & 7 & 11.7 \\
\hline Erosive Oesophagitis & 6 & 10.0 \\
\hline Duodenitis & 6 & 10.0 \\
\hline Antral gastritis & 5 & 8.3 \\
\hline Pan gastritis & 5 & 8.3 \\
\hline Duodenal ulcer & 3 & 5.0 \\
\hline Mallory Weiss Tear & 3 & 5.0 \\
\hline GAVE(Gastric Antral Vascular Ectasia) & 1 & 1.7 \\
\hline Carcinoma oesophagus & 1 & 1.7 \\
\hline Gastro-oesophageal Varices type-I (GOV Type-I) & 1 & 1.7 \\
\hline Normal & 2 & 3.4 \\
\hline
\end{tabular}


This table shows OGDscopy findings among study subjects. Most commonly observed were oesophageal varices $(51.6 \%)$, Portal hypertensive gastropathy $(33.3 \%)$, hemorrhagic gastritis
$(13.3 \%)$ and among less frequent findings were GAVE, carcinoma oesophagus $1.7 \%$ each. only $3.4 \%$ had normal findings on OGDscopy.

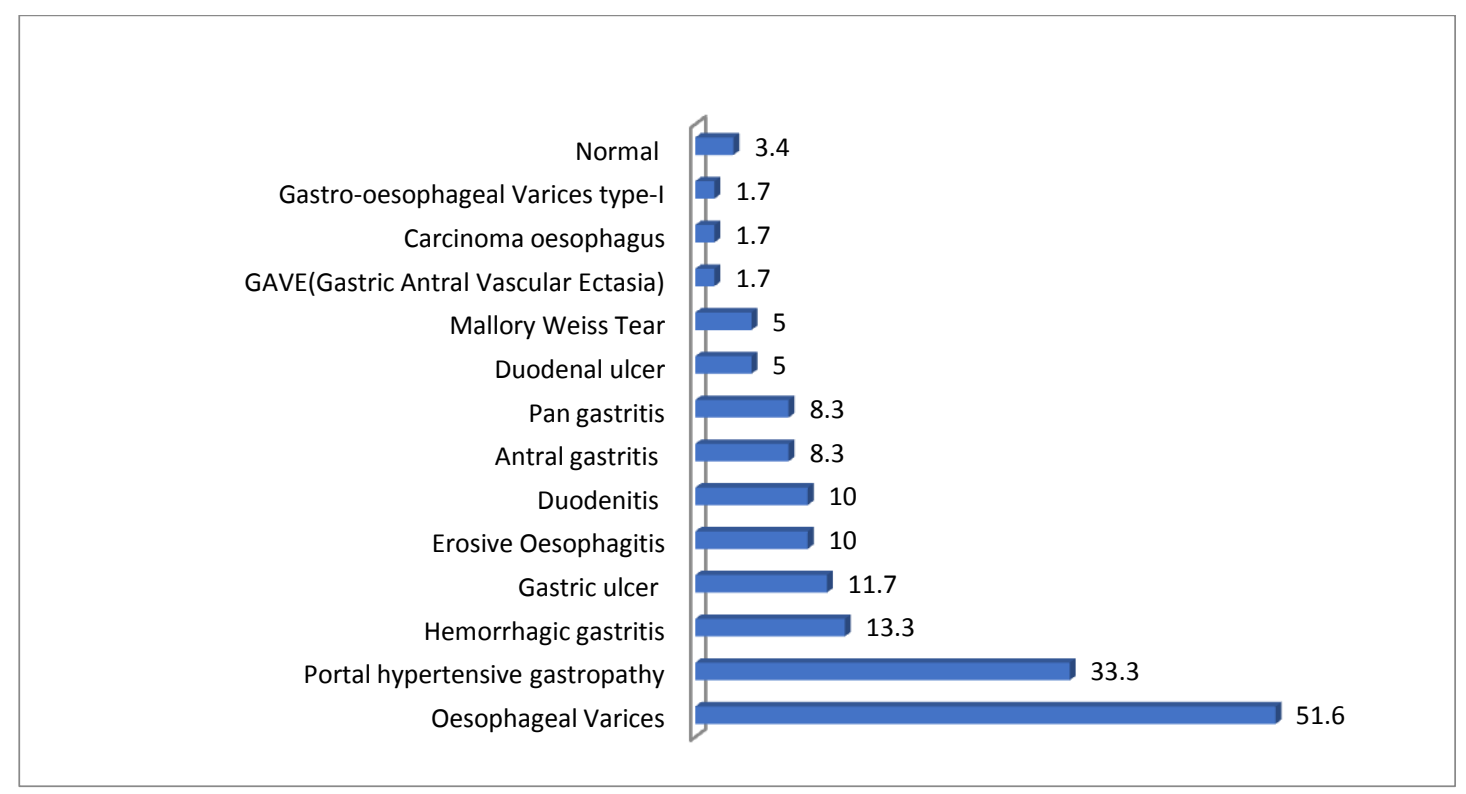

Figure 5: OGDscopy findings among study subjects

Table 6: Relation between Rockall outcome and Risk factors among study subjects

\begin{tabular}{|l|c|c|c|c|}
\hline \multirow{2}{*}{ Risk factors } & \multicolumn{2}{|c|}{ Rockall Outcome } & \multirow{2}{*}{ Total } & P value \\
\cline { 2 - 3 } & Good & Poor & & 0.0002 \\
\hline Alcohol & $9(31.1 \%)$ & $30(76.9 \%$ & 39 & 0.470 \\
\hline Smoking & $5(55.5 \%)$ & $4(44.5 \%)$ & 9 & NA \\
\hline NSAIDs use & $5(100 \%)$ & 0 & 5 & NA \\
\hline HBsAg & 0 & $1(100 \%)$ & 1 & NA \\
\hline Hep C & 0 & $1(100 \%)$ & 1 & \\
\hline
\end{tabular}

This table shows relation between severity of bleeding and risk factors among study subjects. There was significant difference in severity of bleeding and alcoholism with statistically significant value $(\mathrm{p}=0.001)$. Among smokers, 77.8 $\%$ had minor bleeding, among NSAIDs users, $100 \%$ found with minor bleeding.

\section{Discussion}

UGIB is a significant and potentially life threatening problem worldwide. Despite various advances in diagnosis and treatment, mortality and morbidity has remained more or less constant.

Minimum age of presentation in our study was 18 years and maximum age was 82 years and mean age was $41.93 \pm 15.16$ years and most of the patients were in age between $31-40$ years (31.7
\%).In a study conducted by Anand D et al (8) mean age of presentation was $49 \pm 14.26$ years. In another study by Shah $\mathrm{H}$ et $\mathrm{al}^{(6)}$, mean age of presentation was 45.56 years.

In the present study, the ratio of male and female was 6.5: 1 showing male predilection which was comparable to the study conducted by Singh S P et $\mathrm{al}^{(9)}$ where the ratio of male and female was 6 : 1.In our study, most common mode of presentation of UGIB is hematemesis and melena which was seen in 31 patients $(51.7 \%)$. In a similar study done by Anand D et al ${ }^{(8)}$, clinical presentation were both hematemesis as well as melena in $68(59.64 \%)$ patients, only hematemesis occurred in $31(27.19 \%)$ patients and only melena in $14(12.28 \%)$ patients. Alcohol consumption, smoking and use of NSAIDs are 
well known risk factors associated with UGIB. In our study, $65 \%$ of patients were alcohol consumer and incidence of UGIB was seen more in them showing a positive correlation between them $(\mathrm{p}=0.001)$ which coincides well with the study done by Chaudhary $S$ et $\mathrm{al}^{(10)}$. Upper GI bleed was categorized into minor, moderate or massive, depending on hemodynamic assessment ${ }^{(11)}$. Based on this, it was found majority of patients presented with minor bleeding (55\%). In the present study, $50 \%$ study subjects had portal vein collaterals, 43.3\% had ascites, $40 \%$ had splenomegaly. In a study done by Shangavi $\mathrm{Y}$ et al ${ }^{(12)}$, the commonest abnormality detected was altered echotexture of liver followed by splenomegaly in $19.04 \%$ patients and dilated portal vein in $11.11 \%$ patients. Sarwar et al. ${ }^{(13)}$ found that patients having portal vein diameter of more than $11 \mathrm{~mm}$ are more likely to develop oesophageal varices. Etiological causes of UGIB are variable in various studies done in India with some of them showing variceal bleed while others showing peptic ulcer disease as the most common cause for UGIB. In our study, oesophageal varices were seen in 51.6 $\%$ patients. In a similar study done by Shah $\mathrm{H}$ et $\mathrm{al}^{(6)}$, oesophageal varices $(46.3 \%)$ was the commonest cause of UGIB followed by Mallory Weiss tear in $18.3 \%$ patients. In a study conducted by Anand D et $\mathrm{al}^{(8)}$ oesophageal and gastric varices $(56.14 \%)$ was found to be the commonest cause of UGIB followed by peptic ulcer. Rockall scoring system helps in predicting the deaths and patients who are at high risk for rebleeding $^{(14)}$. In present study, mean Rockall score was $3.58 \pm 2.22$ indicating that most patients belonged to the high risk category. There was a statistically significant difference $(p=0.001)$ showing poor Rockall outcome in alcoholics.

\section{Conclusion}

The majority of patients belonged to the age group of 31-40 years, with a male predilection. Most cases presented with minor or moderate upper GI bleed, with massive bleeds occurring only in minority. This study showed that variceal bleed was the commonest cause of upper GI bleeding in our patients.

\section{References}

1. Jutabha R, Jensen DM, Friedman SL, McQuaid KR, Grendel JH. Acute Upper Gastrointestinal Bleeding, Current Diagnosis \& Treatment in Gastroenterology. Mcgraw-Hill 2'’d edition inc.2003;53.

2. Thomopoulos KC, Vagenas KA, Vagianos CE, Margaritis VG, Blikas AP, Katsakoulis EC et al. Changes in aetiology and clinical outcome of acute upper gastrointestinal bleeding during the last 15 years. Eur J Gastroenterol Hepatol 2004;16:177-182.

3. Stanley AJ. Update on risk scoring systems for patients with upper gastrointestinal haemorrhage. World J Gastroenterol 2012; 18(22): 2739-2744.

4. Marshall JK, Collins SM, Gafni A. Prediction of resource utilization and case cost for acute nonvariceal upper gastrointestinal hemorrhage at a Canadian community hospital. Am J Gastroenterol. 1999; 94: 1841-6.

5. Jain J, Rawool A, Banait S, Maliye C. Clinical and endoscopic profile of patients with upper gastrointestinal bleeding in central rural India: A hospital based cross sectional study. JMGIMS 2018, Vol 23; Issue 1: 13-18.

6. Shah H, Manohar TP. Clinical and endoscopic parameters of upper gastrointestinal bleeding. International journal of community health and medical research. 2016; Vol 2; Issue 1:8-13.

7. Jaskolka JD, Binkhamis S, Prabhudesai V, Chawla TP. Acute gastrointestinal haemorrhage: Radiologic diagnosis and management. Can Assoc Radiol J 2013; 64:90-100.

8. Anand D, Gupta R, Dhar M, Ahuja V. Clinical and endoscopic profile of patients 
with upper gastrointestinal bleeding at tertiary care center of North India. J Dig Endosc 2014;5: 139-43.

9. Singh SP, Panigrahi MK. Spectrum of upper gastrointestinal haemorrhage in coastal Odisha. Trop Gastroenterol 2013; 34: 14-17.

10. Chaudhary S, Shakya S, Jaiswal N, Shahi A, Dhakal P, Chaudhary N. Clinical profile and outcome of patients presenting with acute upper gi bleeding in a tertiary care

11. Centre of western Nepal. Journal of Universal College of Medical Sciences.2018, 6(1):3-7

12. Rockey DC, Gastrointestinal bleedingclinical presentation. Gastroenterol Clin of North America 34(2005) 581-582.

13. Shangavi Y, Rathod B J, Yagnik D Y. A clinical study on etiology, prognosis, outcome and role of endoscopy in upper gastrointestinal bleed in a tertiary care center. Internet Journal of Medical Update;2017 July; 12(2):4-9.

14. Sarwar S, Khan AA, Alam A. NonEndoscopic Prediction of presence of Oesophageal varices in Cirrhosis. J Coll Physicians Surg. Pak 2005; 15(9): 528=31.

15. Rockall TA, Logan RF, Devlin HB, Northfield TC. Risk assessment after acute upper gastrointestinal hemorrhage. Gut. 1996;38: 316-21.

\section{Abbreviations}

GI- Gastrointestinal

UGIB- Upper Gastrointestinal bleeding

OGD- Oesophagogastroduodenoscopy

NSAIDS- Non steroidal anti-inflammatory drugs

GAVE- Gastric Antral vascular ectasia 